University of Nebraska - Lincoln

DigitalCommons@University of Nebraska - Lincoln

U.S. Department of Veterans Affairs Staff

Publications

U.S. Department of Veterans Affairs

2009

\title{
Comparative Analysis of Pain During Anesthesia and No-scalpel Vasectomy Procedure Among Three Different Local Anesthetic Techniques
}

\author{
Himanshu Aggarwal \\ Duke University Medical Center, himanshu.aggarwal@duke.edu \\ Rei K. Chiou \\ Creighton University Medical Center, rchiou@dchealthnet.com \\ Larry E. Siref \\ University of Nebraska Medical Center \\ Stewart E. Sloan \\ University of Nebraska Medical Center
}

Follow this and additional works at: https://digitalcommons.unl.edu/veterans

Aggarwal, Himanshu; Chiou, Rei K.; Siref, Larry E.; and Sloan, Stewart E., "Comparative Analysis of Pain During Anesthesia and No-scalpel Vasectomy Procedure Among Three Different Local Anesthetic Techniques" (2009). U.S. Department of Veterans Affairs Staff Publications. 24.

https://digitalcommons.unl.edu/veterans/24

This Article is brought to you for free and open access by the U.S. Department of Veterans Affairs at DigitalCommons@University of Nebraska - Lincoln. It has been accepted for inclusion in U.S. Department of Veterans Affairs Staff Publications by an authorized administrator of DigitalCommons@University of Nebraska - Lincoln. 


\title{
Comparative Analysis of Pain During Anesthesia and No-scalpel Vasectomy Procedure Among Three Different Local Anesthetic Techniques
}

\author{
Himanshu Aggarwal, Rei K. Chiou, Larry E. Siref, and Stewart E. Sloan
}

OBJECTIVES

To compare the pain during anesthesia and during the no-scalpel vasectomy procedure for local infiltration anesthesia (LIA), LIA supplemented with spermatic cord block (LIA + SCB), and no needle jet anesthesia.

METHODS

Bilateral no-scalpel vasectomy was performed in 323 patients during 2007. Of the 323 patients, 65 received LIA, 29 received LIA + SCB, and 227 received anesthesia using the no-needle technique with the MadaJet device. The level of pain during anesthesia administration and the subsequent procedural pain was documented for each technique using a pain scale of 0-10.

RESULTS Pain during the LIA + SCB procedure (mean $1.7 \pm 1.6$ ) was significantly less than the pain during LIA (mean $3.3 \pm 2.3 ; P<.01$ ). No statistically significant difference was found between the levels of pain experienced during LIA + SCB and no-needle jet anesthesia $(P>>.01$ and $P>>.05$, respectively). Intraoperative pain after LIA + SCB (mean $0.64 \pm 1.2$ ) was significantly less than the intraoperative pain after LIA (mean $2.7 \pm 2.6 ; P<<<.01$ ). Also, the intraoperative pain after LIA + SCB was significantly less than the intraoperative pain after no-needle jet anesthesia (mean $2.13 \pm 2.0 ; P<<<.01$ ).

CONCLUSION LIA + SCB is an effective and better method of anesthesia compared with LIA alone or no-needle jet anesthesia for reducing the pain during vasectomy. Also, no difference was found in the pain levels during anesthesia for the LIA + SCB, LIA, and no-needle anesthesia techniques. UROLOGY 74: 77-81, 2009. (c) 2009 Elsevier Inc.

$\mathrm{V}$ asectomy is the safest and most inexpensive option for permanent male sterilization. ${ }^{1}$ It is the most common urologic procedure performed, and approximately 500000 vasectomies are performed annually, at a rate of approximately 10/1000 men in the United States. ${ }^{2}$ No-scalpel vasectomy is the most commonly performed technique of vasectomy because of the small incision size, short procedure time, and lower incidence of scrotal hematoma formation, pain, and other complications. ${ }^{3-7}$ For the same reason, the percentage of vasectomies performed using no-scalpel vasectomy and the number of physicians who reported that they use no-scalpel vasectomy increased substantially in past decade. ${ }^{2}$ However, 1 of the barriers to increased acceptance

\footnotetext{
From the Division of Urology, Creighton University Medical Center; Division of
Urology, University of Nebraska Medical Center; Division of Urology, Department of

From the Division of Urology, Creighton University Medical Center; Division of
Urology, University of Nebraska Medical Center; Division of Urology, Department of Veterans Affairs; and Western Iowa Healthcare System, Midwest Urology Associates
and Urology Specialists, Immanuel Plaza West, Omaha, Nebraska
Reprint requests: Himanshu Aggarwal, M.D., Department of Surgery, Duke UniVeterans Affairs; and Western Iowa Healthcare System, Midwest Urology Associates
and Urology Specialists, Immanuel Plaza West, Omaha, Nebraska
Reprint requests: Himanshu Aggarwal, M.D., Department of Surgery, Duke UniVeterans Affairs; and Western Iowa Healthcare System, Midwest Urology Associates
and Urology Specialists, Immanuel Plaza West, Omaha, Nebraska
Reprint requests: Himanshu Aggarwal, M.D., Department of Surgery, Duke University Medical Center, 405 Dovershire Parkway, Durham, NC 27704. E-mail: himanshu.aggarwal@duke.edu

Submitted: October 5, 2008, accepted (with revisions): November 15, 2008
}

() 2009 Elsevier Inc.

This article is a U.S. government work, and is not subject to copyright in the United States of vasectomy is the fear of pain associated with the local anesthetic.

Different local anesthesia techniques have been used for no-scalpel vasectomy. The most frequently used anesthesia technique for no-scalpel vasectomy is local infiltration anesthesia (LIA) at the site of the resection, ${ }^{3}$ with additional infiltration in the external spermatic sheath. ${ }^{8}$ A few studies have reported that the supplement of LIA with some additional blocks significantly reduces the pain during vasectomy. According to a study of intra-vas deferens bupivacaine injection significantly reduced the intraoperative pain and long-term chronic postvasectomy pain ${ }^{9}$ in patients undergoing vasectomy. In another study, the inguinal funicular block using 10 $\mathrm{mL}$ of $1 \%$ carbocaine was used as a supplement to LIA, with significantly less intraoperative pain on the side of the active inguinal funicular block. ${ }^{10}$ In another study, a eutectic mixture of local anesthetic cream was applied by patients 1 hour before the scheduled time of surgery as a supplement to LIA, but it did not significantly decrease the procedural pain. ${ }^{11}$ Another technique of anesthesia used for vasectomy is a no-needle anesthetic technique for no-scalpel vasectomy. It was first used in 2001 for 
vasectomy. ${ }^{12}$ This method uses a jet injection device to administer the local anesthetic for no-scalpel vasectomy. This device generates a high-pressure spray that forces anesthetic solution through the skin, vas, and surrounding vasal tissues, providing a complete anesthetic block of the vas. ${ }^{12,13}$ Some studies have claimed the superiority of this technique compared with the LIA technique in terms of reduced complications and intraoperative pain. ${ }^{14}$ However, only 1 study has compared these 2 techniques, and no statistically significant difference was found between the 2 techniques in terms of intraoperative pain. ${ }^{15}$

In the present study, we compared the pain during anesthesia and during the vasectomy procedure using different techniques of local anesthesia: LIA, LIA supplemented with spermatic cord block (SCB), and the no-needle jet anesthesia technique for no-scalpel vasectomy.

\section{MATERIAL AND METHODS}

Bilateral no-scalpel vasectomy was performed in the standard manner using open access with a round clamp technique by 3 experienced, board-certified urologists in 323 patients during 2007. Patient age ranged from 25 to 55 years (mean 37.95). Three different techniques of local anesthesia (ie, LIA, LIA + $\mathrm{SCB}$, and the no-needle jet anesthesia technique) were used in these patients. Of these 323 patients, 65 underwent standard LIA, 29 LIA + SCB, and 227 the no-needle jet anesthesia technique. Two patients were referred after failure of a previous attempt of vasectomy because of a contracted scrotum. In these patients, LIA had been used during the previous failed attempts, and LIA + SCB was used during subsequent attempt. After the procedure, the patients were asked to complete a pain scale questionnaire immediately or to return the questionnaires sent to them by mail. The level of pain during the anesthesia and subsequent procedural pain was documented for each technique according to a pain scale of $0-10$, with 0 being no pain and 10 being the most extreme pain of their life. In the 2 patients, who were referred after a previous failed attempt at vasectomy, the pain assessment was done during the anesthesia and the operation separately for both attempts. The patients were categorized as follows: those with no pain/minimal pain had a pain score of $0-1$, those with mild pain had a pain score of 2-3, those with moderate pain had a pain score of 4-7, and those with severe pain had a pain score of 8-10.

\section{Standard LIA}

The external genitalia were cleansed using a $10 \%$ povidoneiodine solution and draped in a sterile fashion. In the standard procedure, the vasal nerve was blocked with $2-3 \mathrm{~mL}$ of $1 \%$ lidocaine using a 1.5 -in.-long 25 -gauge needle. Initially, a single wheal was raised at the juncture of the superior and medial third of the scrotum skin. Then, the needle was advanced deeply and proximally up to the external inguinal ring along the perivasal sheath while injecting $2-3 \mathrm{~mL}$ of anesthetic solution. After 2-3 minutes of waiting, no-scalpel vasectomy was performed in the standard manner.

\section{LIA + SCB}

After cleaning the external genitalia with a $10 \%$ povidoneiodine solution and draping in a sterile fashion, the spermatic cord was gently grasped at the root of scrotum between the left thumb and index finger and injected with an anesthetic solution using an ultra-fine (ie, 0.5-in., 30-gauge) hypodermic needle. The entire cross-section of the spermatic cord and its surrounding rim were injected with the anesthetic solution. This was ensured by an incremental $20^{\circ}$ readjustment of the angle/direction of the needle after each pass/injection through the spermatic cord. An equal mixture of $1 \%$ lidocaine with epinephrine at 1:100 000 and $0.5 \%$ Marcaine was used as the anesthetic solution. An average of $4 \mathrm{~mL}$ was used to anesthetize each spermatic cord. Next, the vas was palpated, and 1-2 mL of local anesthesia was administered on the scrotal skin. After 1 minute of waiting, no-scalpel vasectomy was performed in the standard manner.

\section{No-Needle Anesthesia Using MadaJet Injection Device}

The MadaJet (Mada Medical Products, Carlstadt, NJ) device was used for the no-needle injection technique according to the manufacturer's guidelines. Using a sterile technique, 1 drop of lidocaine solution was placed over the seal on the injector head to promote a good seal with the filling chamber, and the filling chamber was filled with approximately $4 \mathrm{~mL}$ of $2 \%$ lidocaine without epinephrine. After cleaning the scrotal skin with an alcohol swab, the first injection was made over the right vas deferens at the median raphe at the junction of the upper one third and lower two thirds of the scrotum. Two more injections were made 3-5 mm apart going distally from the first injection. The same technique was used for the left vas deferens, except that 3 injections were applied to the right lateral aspect of the median raphe adjacent to the previous injections. After waiting for 1 minute, no-scalpel vasectomy was performed in a standard manner.

\section{Statistical Analysis}

The endpoints of the pain scores were analyzed using the single-factor analysis of variance, and the level of significance was expressed at $P<.01$ after Bonferronie's correction, taking into consideration the different numbers of patients undergoing each of the 3 different techniques. The data were analyzed using the Statistical Package for Social Sciences (SPSS, Chicago, IL) statistical software, and graphs were made using GraphPad Prism.

\section{RESULTS}

Of the 65 patients who underwent LIA, 26 answered the questionnaires. Of the 29 patients who underwent LIA + SCB, 25 answered the questionnaires. Of the $227 \mathrm{pa}-$ tients who underwent no-needle jet anesthesia, 72 answered the questionnaires.

The percentage of patients with different pain scores, for all 3 techniques, during anesthesia and the vasectomy procedure is listed in Tables 1 and 2, respectively. The categorization and comparison of the percentage of pain scores for all 3 techniques during the anesthesia and during the procedure is shown in Figures 1 and 2, respectively. 
Table 1. Percentage of patients with visual analog pain scores during anesthesia stratified by anesthesia technique

\begin{tabular}{|c|c|c|c|c|c|c|c|c|c|c|c|}
\hline \multirow[b]{2}{*}{ Technique } & \multicolumn{11}{|c|}{ Pain During Anesthesia (\% of Patients) } \\
\hline & 0 & 1 & 2 & 3 & 4 & 5 & 6 & 7 & 8 & 9 & 10 \\
\hline $\operatorname{LIA}(n=26)$ & - & 11.54 & 38.46 & 15.38 & 15.38 & 3.85 & - & 7.69 & 3.85 & - & 3.85 \\
\hline LIA + SCB $(n=25)$ & 24.00 & 28.00 & 20.00 & 12.00 & 12.00 & - & 4.00 & - & - & - & - \\
\hline $\begin{array}{l}\text { No-needle anesthesia } \\
\quad(\mathrm{n}=72)\end{array}$ & 16.67 & 26.39 & 18.06 & 20.83 & 2.78 & 11.11 & - & 1.39 & 2.78 & - & - \\
\hline
\end{tabular}

LIA, local infiltration anesthesia; SCB, spermatic cord block.

Table 2. Percentage of patients with visual analog pain scores during vasectomy stratified by anesthesia technique

\begin{tabular}{lccccccccccc}
\hline & \multicolumn{7}{c}{ Pain During Surgery (\% of Patients) } \\
\cline { 2 - 9 } Technique & 0 & 1 & 2 & 3 & 4 & 5 & 6 & 7 & 8 & 9 & 10 \\
LIA $(\mathrm{n}=26)$ & 19.23 & 19.23 & 26.92 & 3.85 & 15.38 & - & - & 7.69 & 3.85 & 0.00 & 3.85 \\
LIA + SCB $(\mathrm{n}=25)$ & 68.00 & 16.00 & 8.00 & - & 8.00 & - & - & - & - & - & - \\
No-needle anesthesia & 22.22 & 25.00 & 16.67 & 15.28 & 11.11 & 1.39 & 2.78 & 4.17 & 1.39 & - \\
$\quad(n=72)$ & & & & & & & & \\
\hline
\end{tabular}

Abbreviations as in Table 1.

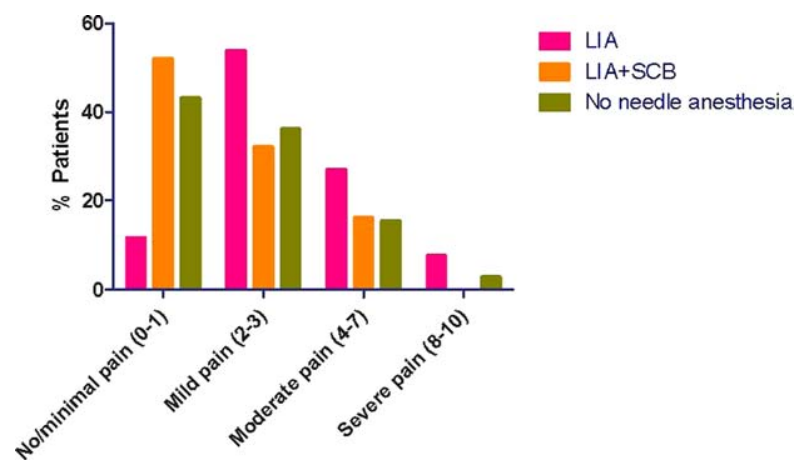

Figure 1. Comparative analysis of pain scores during anesthesia among 3 techniques.

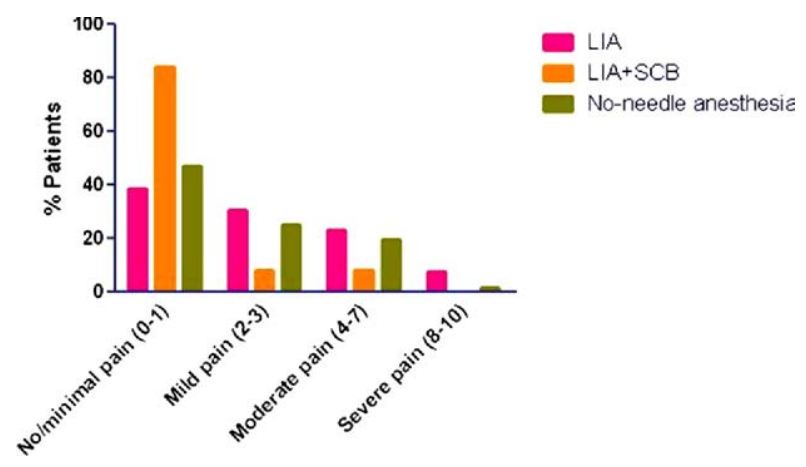

Figure 2. Comparative analysis of intraoperative pain scores among 3 techniques.

The average pain score for LIA was $3.3 \pm 2.3$ (range 1-10), for LIA + SCB was $1.7 \pm 1.6$ (range 0-6), and for no-needle jet anesthesia was $2.2 \pm 1.9$ (range $0-8$ ). The pain with LIA + SCB was significantly less than the pain with LIA during the procedure $(P<.01)$. Also, the pain with the no-needle jet anesthesia was significantly less than the pain with standard LIA $(P<.01)$. However, no statistically significant difference was found between the levels of pain with LIA + SCB and no-needle jet anes- thesia $(P>>.01$ and $P>>.05$, respectively). Two patients, who were referred after a previous failed vasectomy attempt, answered the questionnaires both times. Their pain score during the previous attempt, in which only LIA was used, was 4 and 6 , and the pain score after the second time, in which LIA + SCB was used, was 2 and 0 . This shows that the level of pain during LIA + SCB was less than the level of pain during LIA.

The average pain score for interoperative pain with LIA was $2.7 \pm 2.6$ (range $0-10$ ), with LIA + SCB, it was $0.64 \pm 1.2$ (range 0-4), and with no-needle jet anesthesia, it was $2.13 \pm 2.0$ (range $0-9$ ). The intraoperative pain after LIA + SCB was significantly less than the pain after LIA $(P<<<.01)$. Also, the intraoperative pain after LIA + SCB was significantly less than the pain after no-needle jet anesthesia $(P<<<.01)$. However, no statistically significant difference was found between the levels of intraoperative pain after LIA and no-needle jet anesthesia $(P>>>.05$ and $P>>>.01$, respectively).

Two patients, who were referred after a previoous failed attempt at vasectomy, answered the questionnaires both times for intraoperative pain. Their pain score for intraoperative pain during the previous attempt, in which only LIA was used, was 8 and 4 , and the pain score after the second time, in which LIA + SCB was used, was 0 and 0 . This shows that the intraoperative pain levels after LIA + SCB were much less than the level of pain with standard LIA.

\section{COMMENT}

Vasectomy is 1 of the safest and effective permanent sterilization methods of male contraception. It is adopted as a method of contraception by approximately $9 \%$ of couples in the United States. ${ }^{16}$ With the introduction of no-scalpel vasectomy, its acceptance has increased widely in the past decade owing to the decreased operative pain, shorter procedure time, and lower complication rates. For these reasons, in some parts of China, it has reversed the 
male/female ratio of elective sterilization from $1: 3$ to 3:1. ${ }^{17}$ Various improvements have been made to decrease the pain during the administration of anesthesia and the intraoperative pain. Many people have recommended the supplementation of standard LIA with some additional blocks to decrease the pain during vasectomy. ${ }^{8-11}$

In 2001, Wilson ${ }^{12}$ introduced the no-needle anesthesia technique for vasectomy. Earlier, this technique had been used successfully by dentists, podiatrists, and other medical specialists. ${ }^{18,19}$ Weiss and $\mathrm{Li}^{14}$ demonstrated that this technique results in low pain scores. Only 1 study has compared this technique with LIA and demonstrated that it resulted in low pain scores during the anesthesia but with no statistically significant difference for the intraoperative pain scores between these 2 techniques. ${ }^{14}$ SCB is a simple, safe, and highly effective method of anesthesia for scrotal procedures. It has been used as an effective and safe method for outpatient testicular procedures. $^{20,21}$ We compared LIA, LIA + SCB, and noneedle jet anesthesia performed by 3 experienced urologists. Michael et al. ${ }^{15}$ demonstrated that the average standard pain score for LIA and no-needle jet anesthesia was 2.12 and 1.56 , respectively. In contrast, in a study by Weiss and $\mathrm{Li},{ }^{14}$ the average no-needle jet anesthesia pain score was 1.71 . In the present study, the average standard LIA pain score and no-needle jet anesthesia pain score was $3.3 \pm 2.3$ and $2.2 \pm 1.9$, respectively. For LIA + $\mathrm{SCB}$, the pain score was $1.7 \pm 1.6$. The pain was significantly less during no-needle jet anesthesia and the LIA + SCB technique compared with standard LIA alone. Also, no statistically significant difference was found between the pain scores for LIA + SCB and no-needle jet anesthesia. Approximately $43 \%$ of patients in the noneedle jet anesthesia group and $52 \%$ of patients in the LIA + SCB group had no or minimal pain compared with only $11 \%$ patients in the LIA group (Fig. 1). This also implies that LIA + SCB and no-needle jet anesthesia result in less pain than standard LIA during the anesthesia procedure. Weiss and $\mathrm{Li}^{14}$ also demonstrated the superiority of no-needle jet anesthesia vs. standard LIA. In our 2 referred patients during the first attempts at vasectomy, standard LIA was used alone, and their pain scores during anesthesia were 4 and 6 , and these scores decreased to 0 and 2 during the second attempt when LIA + SCB was used. This also demonstrates the superiority of LIA + SCB compared with LIA alone. The reason for this could be that for $\mathrm{LIA}+\mathrm{SCB}$, a 30-gauge hypodermic needle was used instead of a 25-gauge needle, which was used for standard LIA. The pain score for intraoperative pain in the study by Michael et al..$^{15}$ was 1.68 and 1.86 for no-needle jet anesthesia and standard LIA, respectively. In contrast, in the study by Weiss and $\mathrm{Li}^{14}{ }^{14}$ the pain score for intraoperative pain using noneedle jet anesthesia was 0.66 . In the present study, the average visual analog scale pain score for interoperative pain with standard LIA was $2.7 \pm 2.6$ and for no-needle jet anesthesia was $2.13 \pm 2.0$; the pain score for LIA +
SCB was $0.64 \pm 1.2$. Thus, $\mathrm{LIA}+\mathrm{SCB}$ resulted in significantly less pain during vasectomy than LIA alone and no-needle jet anesthesia, with no difference found in the pain scores between LIA and no-needle jet anesthesia during the procedure. Weiss and $\mathrm{Li}^{14}$ also showed that no significant difference was present in the pain scores during the vasectomy procedure between no-needle jet anesthesia and standard LIA. This is also evident in Figure 2 , which shows that $84 \%$ of patients in the LIA + SCB group had no/minimal pain compared with $38 \%$ and $47 \%$ patients, respectively, in the standard LIA and no-needle jet anesthesia groups. In 2 referred patients during the first vasectomy attempts, standard LIA was used alone. Their pain scores during the procedure were 8 and 4 , and these scores decreased to 0 and 0 during the second attempt at vasectomy, when LIA + SCB was used. This also demonstrates the superiority of LIA + SCB over LIA in terms of intraoperative pain.

\section{CONCLUSIONS}

The results of our study have shown that LIA + SCB is an effective and better method of anesthesia compared with LIA alone and no-needle jet anesthesia for reducing the pain during vasectomy. Also, no difference was found in the pain levels during anesthesia using LIA + SCB, LIA, or no-needle anesthesia. However, additional studies, including randomized control trials, are warranted to confirm these findings.

Acknowledgment. We are very thankful to Ms. Sandy Teel and Ms. Mary Knott for their help in collecting the data.

\section{References}

1. Hendrix NW, Chauhan SP, Morrison JC. Sterilization and its consequences. Obstet Gynecol Surv. 1999;54:766-777.

2. Barone MA, Hutchinson PL, Johnson CH, et al. Vasectomy in the United States, 2002. J Urol. 2006;176:232-236.

3. Li S, Goldstein M, Zhu J, et al. The no-scalpel vasectomy. J Urol. 1991;145:341-344.

4. Huber D. No-scalpel vasectomy: the transfer of a refined surgical technique from China to other countries. Adv Contracept. 1989;5: 217-218.

5. Nirapathpongporn A, Huber DH, Krieger JN. No-scalpel vasectomy at the King's birthday vasectomy festival. Lancet. 1990;335: 894-895.

6. Viladoms Fuster JM, Shihua LP. No-scalpel vasectomy. Arch Esp Urol. 1994;47:695-701.

7. Kumar V, Kaza RM, Singh I, et al. An evaluation of the noscalpel vasectomy technique. BJU Int. 1999;83:283-284.

8. Li PS, Li SQ, Schlegel PN, et al. External spermatic sheath injection for vasal nerve block. Urology. 1992;39:173-176.

9. Paxton LD, Huss BK, Loughlin V, et al. Intra-vas deferens bupivacaine for prevention of acute pain and chronic discomfort after vasectomy. Br J Anaesth. 1995;74:612-613.

10. Rasmussen LA, Sørensen EW, Sørensen C, et al. [Inguinal funicular block in vasectomy]. Ugeskr Laeger. 1994;156:3501-3502.

11. Thomas AA, Nguyen CT, Dhar NB, et al. Topical anesthesia with EMLA does not decrease pain during vasectomy. J Urol. 2008;180: 271-273.

12. Wilson CL. No-needle anesthetic for no-scalpel vasectomy. Am Fam Physician. 2001;63:1295-1295.

13. Monoski MA, Li PS, Baum N, et al. No-scalpel, no-needle vasectomy. Urology. 2006;68:9-14 
14. Weiss RS, Li PS. No-needle jet anesthetic technique for no-scalpel vasectomy. J Urol. 2005;173:1677-1680.

15. Michael A, White MA, Maatman TJ. Comparative analysis of effectiveness of two local anesthetic techniques in men undergoing no-scalpel vasectomy. Urology. 2007;70:1187-1189.

16. Dassow P, Bennett JM. Vasectomy: an update. Am Fam Physician. 2006;74:2069-2074.

17. Liu X, Li S. Vasal sterilization in China. Contraception. 1993;48: 255-65.

18. Munshi AK, Hedge A, Bashir N. Clinical evaluation of the efficacy of anesthesia and patient preference using the needle-less jet sy- ringe in pediatric dental practice. J Clin Pediatr Dent. 2001;25: 131-134.

19. Dialynas M, Hollingsworth SJ, Cooper D, et al. Use of a needleless injection system for digital ring block anesthesia. J Am Podiatr Med Assoc. 2003;93:23-26.

20. Issa MM, Hsiao K, Bassel YS, et al. Spermatic cord anesthesia block for scrotal procedures in outpatient clinic setting. J Urol. 2004;172: 2358-2361.

21. O'Burden RJ, Kelly SW, Sutton D, et al. Spermatic-cord block improves analgesia for day-case testicular surgery. BJU Int. 1997; $80: 472-475$. 